\title{
A UTILIZAÇÃO PARTICULAR OU EMPRESARIAL DE DRONES NO BRASIL: RESPONSABILIDADE CIVIL E AMBIENTAL OU MARCO REGULATÓRIO
}

\author{
Claudia Ribeiro Nunes \\ Universidade Veiga de Almeida (UVA), Rio de Janeiro \\ crpn1968@gmail.com \\ Priscila Elise Alves Vasconcelos \\ Universidade Veiga de Almeida (UVA), Rio de Janeiro \\ prisvascon@gmail.com
}

\begin{abstract}
RESUMO: Este trabalho tem por objetivo demonstrar como as novas tecnologias vêm sendo regulamentadas no Brasil, sendo o núcleo da pesquisa o uso de veículos aéreos não tripulados, os VANT's ou drones. Análise sobre o marco regulatório brasileiro e a verificação de lacunas e diretrizes foi realizada. Através de dados extraídos da legislação, doutrina especializada, artigos científicos e o direito comparado, a pesquisa abrange o mapeamento, os principais aspectos e dimensões envolvendo os drones. Nos resultados, destaca-se a necessidade de melhorias na aplicabilidade e divulgação das regras para pilotagem e uso. Há ausência de normas específicas sobre responsabilidade ambiental e descarte de resíduos tecnológicos.
\end{abstract}

PALAVRAS-CHAVE: Tecnologia. Conflito de competência. Drones. Regulação. Políticas Públicas.

\section{Particular or entrepreneurial use for unmanned aerial vehicles - UAV's - in Brazil: The Regulatory Framework Liability and Environmental Law Analysis}

\begin{abstract}
This paper has an aim adress how the new technologies are being regulated in Brazil, being the object using unmanned aerial vehicles, UAV's or Drones. The work is an analysis on the regulatory framework, a verification guidelines was held and point the gaps. Through the data extracted from the legislation, specialized doctrine, scientific articles and comparative law, the research covers the mapping of the main aspects and dimensions involving drones. In the expecting results, highlighting the need for enhancements on applicability and dissemination of rules for drones pilotage and use. There is lack of specific rules on liability and waste disposal technology.
\end{abstract}

KEYWORDS: Technology. Conflict of competence. UAV's. Regulation. Public policy.

\section{INTRODUÇÃO}

Em pleno século XXI, os antigos aeromodelos tão desejados por jovens e adultos nos anos 70 e 80 deram lugar aos atuais VANT's, veículos aéreos não tripulados, ou drones como são costumeiramente chamados. Os novos aparelhos tomaram os céus das mais diversas cidades e áreas descampadas e fronteiriças ao longo do mundo e vêm sendo utilizados em diferentes acepções econômicas e não econômicas. 
A utilização particular ou empresarial de drones no Brasil: responsabilidade civil e ambiental ou marco regulatório

O avanço tecnológico vem acompanhado de questões fronteiriças do direito ainda não resolvidas. Pode-se citar algumas delas, como a regulação do uso dos drones na segurança pública e privada, nacional e transnacional, tutela ambiental, saúde, desenvolvimento, na modificação dos standarts das novas fontes de energia, dentre outros. Ao dispor sobre o uso de VANT'S ou drones, as áreas de atuação em maior escala são de geomapeamento, agricultura, meio ambiente, segurança e monitoramento, fotos e filmagens, dentre outros (MERCADRONE, 2016).

Este trabalho tem por objetivo demonstrar em qual estágio se encontra a regulamentação dos VANT's ou drones e, para isso, analisará o sistema constitucional brasileiro e as questões referentes a regulação de novas tecnologias $\mathrm{O}$ objeto principal é dessecar as competências concorrentes entre a União e o Estado, verificando se há conflito com a competência local, apelidada na Constituição da República de municipal. Ressalta-se que, por existirem várias espécies de aeronaves VANT's, o trabalho irá abordar de forma global a legislação pertinente citando alguns casos, como o de uso recreativo e da pulverização de fertilizantes, uma das grandes problemáticas atuais.

Para atingir o objetivo geral do trabalho a abordagem metodológica, far-se-á através de revisão da literatura integrada, principalmente, de autores nacionais, além da pesquisa e análise dos dados secundários, como a legislação vigente, a fim de demonstrar como o país - Brasil vem tratando a temática. O método empregado será o estado da arte.

A pesquisa foi realizada através de literatura científica acerca do tema, englobando aspectos jurídico-ambientais e jurídico-econômicos dentro do contexto brasileiro. Foram trazidos dados internacionais de forma a demonstrar a comparação na participação de outros países na temática acerca do uso de novas tecnologias.

O período analisado na pesquisa aborda a evolução histórico-jurídica da legislação brasileira, sendo o marco principal a Politica Nacional de Meio Ambiente de 1981. Outros diplomas de importância justificável também foram abordadas como o surgimento da expressão desenvolvimento sustentável pelo Relatório de Bruntland em 1987, a elevação do tema meio ambiente a direito e garantia fundamental pela Constituição da República em 1988, bem como as principais políticas ambientais que foram implementadas em território brasileiro.

Questões envolvendo a aplicação da Política Nacional de Resíduos Sólidos também foram trazidas à pesquisa, principalmente por se tratar de um dos grandes desafios da atualidade à redução de resíduos e o reaproveitamento para minimizar danos ambientais.

Foram analisados artigos cientificos nas bases de dados nacional e internacional, como Scopus, Web of Science, além de dados governamentais oficiais, sítios eletrônicos de organizações e associações empresariais, e, por fim, literatura jurídica.

Através do uso de palavras-chave como tecnologia, conflito de competência, drones, regulação e políticas públicas, foi possível o levantamento de dados e informações para o desenvolvimento da pesquisa. Por fim, para registro, serão aludidos casos controvertidos na Europa que suscitam um estudo específico e mais aprofundado.

Nesta pesquisa, como não faz parte do escopo de estudo, houve uma limitação para apurar nos meios de comunicações dados para futura pesquisa. Apresenta-se um apanhado de notícias de 2017 e 2018 sobre a temática a auxiliar no entendimento da conclusão sobre o estágio da regulação brasileira. Em trabalho futuro, será realizado o estudo comparativo da regulação brasileira com a de outros países. 


\section{VANT'S OU DRONES}

VANT's ou Drones são aeronaves que voam sem tripulação. Eles também são chamados de VANT (sigla para veículo aéreo não tripulado) ou VANT's, ou UAV (Unmanned Aircraft Vehicle). Existem outras distinções importantes, por exemplo, os mísseis de cruzeiro não são considerados drones pela simples razão de que eles não são reutilizáveis e os drones são.

Há inúmeros tipos de drones de acordo com seu uso. Formas e tamanhos também são muito variados. No início, os drones eram controlados por pessoas via controle remoto. Hoje, as expectativas do controle autônomo dos drones crescem. Estas são as duas modalidades fundamentais.

No cenário militar, drones são usados para missões de reconhecimento e ataque. Na esfera civil, seus usos são múltiplos e continuam crescendo. Há drones para combater incêndios, para busca e salvamento, patrulhamento de estradas, filmagem de filmes, etc. Eles são especialmente úteis no trabalho em áreas perigosas ou inacessíveis. O que ganhou impulso como uma indústria destinada a fins bélicos - especialmente as forças dos EUA - tornou-se, pouco a pouco, uma presença maior na esfera civil.

Atualmente, mais de 70 países possuem drones e, em vários países, há fabricantes dessa tecnologia originários de grandes empresas, pesquisadores de universidades e algumas empresas iniciantes. Os fabricantes desses dispositivos têm interesse em vendê-los e em obter benefícios em escala global. Apenas com o uso militar de drones, os lucros da introdução de suas invenções em escala civil poderiam dobrar, alcançando 11.600 milhões de dólares em 2023, como reconhecido pelo Grupo Teal.

Outras estimativas, como a de Jim Williams, da Administração Federal de Aviação dos Estados Unidos $^{1}$ - FAA, sigla em inglês -, registraram em 90.000 milhões de dólares os lucros que o negócio dos drones poderia gerar na próxima década (Torres, 2014). Ressalta-se que a FAA é o órgão governamental norte-americano responsável pela parte de regulamentação e demais aspectos relacionados à aviação civil nos Estados Unidos.

De certa forma, todos os outros fabricantes de drones de consumo estão seguindo os passos da empresa que iniciou uma base de fãs. Em termos de tecnologia, essas decolagens são raras.

Importante destacar que, na atualidade, a empresa chinesa enfrenta o desafio da concorrência de fabricantes de drones mais baratos. Além disso, as ideias chinesas acabam por confrontar com as disposições legais de mercados tão importantes quanto de países como os Estados Unidos, onde a FAA impede o uso comercial de pequenos drones.

\section{COMPETÊNCIA CONSTITUCIONAL SOBRE NOVAS TECNOLOGIAS}

Ao tratar de regulamentação sobre determinado assunto, é imprescindível verificar o texto constitucional acerca da competência para legislar. Sendo a Constituição da República Federativa do Brasil uma constituição analítica (SLAIBI FILHO, 2003) e econômica (CANOTILHO, 1993), o seu texto evita qualquer discricionariedade pelo legislador e possui preceitos que garantem a organização e funcionamento da economia.

\footnotetext{
1 Federal Aviation Administration. FAA. 1940.
} 
A utilização particular ou empresarial de drones no Brasil: responsabilidade civil e ambiental ou marco regulatório

A República Federativa do Brasil é composta pela união indissolúvel dos seguintes entes: Estados, Municípios e o Distrito Federal ${ }^{2}$ (BRASIL, 1988). Por se tratar de uma constituição analítica, encontra-se em seu texto a descrição das competências dos entes federativos. No artigo 21 da Carta (BRASIL, 1988), o constituinte originário elencou as competências de cada ente, podendo ser privativa, reservada, concorrente ou suplementar.

De acordo com Silva (2015), competência é a faculdade atribuída juridicamente a uma entidade, órgão ou agente do Poder Público para a emissão de decisões. Pela Constituição da República (BRASIL, 1988), adotou-se o principio da prevalência do interesse como forma de designar a competência dos entes federados.

Nesse sentido, cabe a União legislar sobre matérias de interesse geral, aos Estados e Distrito Federal as matérias de interesse regional e, por fim, aos Municípios e ao Distrito Federal aquelas cujo interesse local seja preponderante.

O artigo 21 da Constituição Federal cuida da competência exclusiva da União, enquanto que o artigo 22 trata da sua competência privativa para legislar. Importante destacar que no parágrafo único do artigo 22, há a previsão de lei complementar autorizativa de matérias remanescentes, devidamente especificadas no texto constitucional (BRASIL, 1988).

Já o artigo 23 da Carta (BRASIL, 1988), traz as competências distribuídas entre os entes da federação, sendo as comuns. Cita-se a proteção ao meio ambiente como uma competência comum a todos os entes federativos.

O artigo 24 da Constituição da República (BRASIL, 1988) trata da competência concorrente, ou seja, matérias que competem à União, Estados e Distrito Federal. Caberá a União estabelecer normas gerais enquanto que aos Estados e Distrito Federal aquelas normas específicas.

Importante destacar que o parágrafo $3^{\circ}$ do artigo 24 é claro ao dispor que na ausência de lei federal sobre normas gerais, os Estados exercerão a plenitude de competência, visando atender suas peculiaridades. Trata-se de uma competência suplementar descrita na própria Constituição Federal, onde no caso de superveniência de lei federal sobre a norma geral, ocorre a suspensão da eficácia da norma estadual geral.

O objeto de estudo é a normatização para trafegar veículos aéreos não tripulados, os VANT'S, que circulam no espaço aéreo brasileiro. Mediante isso, é preciso verificar de quem será a competência para legislar e regulamentar o seu uso.

Conforme o artigo 21, inciso XII, alínea c da Constituição da República (BRASIL, 1988), caberá a União a exploração da navegação aérea, podendo fazê-lo de forma direta ou mediante autorização, concessão ou permissão.

Acerca da competência legislativa, é importante destacar que o Supremo Tribunal Federal, em fevereiro de 2018, julgou um caso envolvendo o lançamento aéreo de agrotóxicos na produção de cana-de-açúcar em propriedade localizada no município de Lagoa da Prata, Minas Gerais $^{3}$. Surgiu, então, a discussão acerca do interesse local (municipal) que ensejaria a competência municipal descrita no artigo 30, inciso I da Carta de 1988 (BRASIL, 1988).

Art. 1. Da Constituição da República Federativa do Brasil. Brasil. 1988.

3 Supremo Tribunal Federal. Ag.Reg. no Recurso Extraordinário 1.045.719 Minas Gerais. Julgado em 05 de fevereiro de 2018. 
De acordo com a Egrégia Corte Brasileira, quando há interesse local ocorre a atração da competência legislativa municipal. Porém, é necessário verificar as condições sociais, econômicas e politicas que envolvem o caso. O Supremo Tribunal Federal decidiu pela competência municipal por se tratar de questão legislativa relacionada ao direito ambiental (STF, 2018).

Com o advento da Agência Nacional de Aviação Civil ${ }^{4}$, em 2006, a União Federal exerce a sua competência descrita no art. 21, inciso XII, alínea c da Constituição da República. Através da agência reguladora de âmbito nacional, a União regula e fiscaliza as atividades de aviação civil e de infraestrutura aeronáutica e aeroportuária (BRASIL, 2006).

Outrossim, verifica-se que se trata de matéria de competência da União Federal, que a exerce através de sua agência reguladora desde 2006, ao tratar de aeromodelos não recreativos.

Com relação aos recreativos e de acordo com o exposto, a competência legislativa será a municipal, tendo por fundamento o art. 30, I da Carta de $1988^{5}$.

\subsection{Competência Jurisdicional: VANT'S não-recreativos e recreativos}

Uma das discussões acerca dos drones está relacionado à competência para processar e julgar as demandas judiciais. Para adentrar ao tema, necessário verificar que há os drones nãorecreativos, utilizados pela Aeronáutica por exemplo, cuja competência constitucional é da União Federal (art. 21, inciso XII, alínea $\mathrm{c}^{6}$ ).

Com relação à espécie não-recreativa, como o bem jurídico tutelado é o espaço aéreo, o interesse da União Federal atrai a competência para a Justiça Federal, conforme artigo 109, I da Carta de $1988^{7}$.

Ao abordar a espécie recreativa, é importante verificar que a discussão acerca da competência processual ou jurisdicional traz algumas controvérsias que precisam ser dirimidas. Através da análise do artigo $125, \S 1^{\circ}$, da Constituição da República ${ }^{8}$, verifica-se que a competência dos Tribunais de Justiça Estaduais é residual. Ou seja, assuntos em que há um interesse local ou regional irão tramitar perante a Justiça Estadual.

Diddier Jr (2018) aduz que competência é o fruto de critérios para distribuição entre vários órgãos que possuem jurisdição, sendo a competência jurisdicional o poder em exercer a jurisdição nos limites legais.

Para Nery Jr e Andrade Nery (2017), ao comentarem o artigo 42 do Código de Processo Civil $^{9}$ (BRASIL, 2015), dispõem que os critérios são definidos pela lei, distribuindo entre os órgãos do Estado o poder jurisdicional. Segundo os autores, a lei confere competência ao órgãos estadual capaz de exercer a jurisdição nos limites legais.

4 Brasil. Lei 11.182/2006. Cria a Agencia Nacional de Aviação Civil.

5 Art. 30. Compete aos Municípios: I - legislar sobre assuntos de interesse local;(...). Constituição da República. 1988.

6 Art. 21. Compete à União: XII - explorar, diretamente ou mediante autorização, concessão ou permissão: c) a navegação aérea, aeroespacial e a infraestrutura aeroportuária;(...). Constituição da República. 1988.

7 Art. 109. Aos juízes federais compete processar e julgar: I - as causas em que a União, entidade autárquica ou empresa pública federal forem interessadas na condição de autoras, rés, assistentes ou oponentes (...).Constituição da República. 1988.

8 Art. 125. Os Estados organizarão sua Justiça, observados os princípios estabelecidos nesta Constituição. $§ 1^{\circ} \mathrm{A}$ competência dos tribunais será definida na Constituição do Estado, sendo a lei de organização judiciária de iniciativa do Tribunal de Justiça. (...).Constituição da República. 1988.

9 Art. 42. As causas cíveis serão processadas e decididas pelo juiz nos limites de sua competência, ressalvado às partes o direito de instituir juízo arbitral, na forma da lei. 
A utilização particular ou empresarial de drones no Brasil: responsabilidade civil e ambiental ou marco regulatório

Acerca dessa temática, processualistas como Wambier (2017), define como critérios para o conflito de competência os relacionados a definição e tipo de competência (territorial, valor, em razão da matéria, em razão da pessoa e por função). Com relação à competência territorial, define o autor a necessidade de localização do bem objeto do litígio.

Sendo a temática um veículo aéreo não tripulável - VANT's ou Drones -, de acordo com Wambier (2017) ocorrendo acidentes inclusive com aeronaves recairá no disposto do artigo 53, V do Código de Processo Civil ${ }^{10}$ (BRASIL, 2015). Conforme o dispositivo legal, o foro competente será o do local do acidente, inclusive para reparação de danos.

Arruda Alvim et al.(2018) ao comentarem o artigo 53, inciso V do texto processual civil ${ }^{11}$, sustentam que as demandas de reparação de danos por acidentes que envolvam aeronaves também serão processados e julgados no local do domicilio ou da ocorrência do fato. Ou seja, delitos envolvendo acidentes de veículos ou aeronaves recebem o mesmo tratamento acerca da definição da competência jurisdicional.

\subsection{Drones: A Resolução Da Anac}

De acordo com a ANAC (2017-1), a expressão drone pode ser utilizada para descrever qualquer aeronave ou outro veículo que possua elevado grau de automotismo. A ANAC não utiliza essa nomenclatura e sim aeromodelos ou aeronaves remotamente pilotadas - RPA, sendo a diferença entre elas a finalidade que possuem. Os aeromodelos são utilizados para fins recreativos, enquanto as aeronaves remotamente pilotadas possuem qualquer outra finalidade não recreativa, seja corporativa ou não.

O dia 03 de maio de 2017 foi o marco regulatório acerca do uso de drones. A Agência Nacional da Aviação Civil editou o Regulamento Brasileiro da Aviação Civil Espacial - RBACE (ANAC, 2017-2), elencando as exigências para o uso de aeronaves não tripuladas. De acordo com a norma, deverão ser observadas as regulamentações de outros entes da Administração Pública, como a Agencia Nacional de Telecomunicações - ANATEL, o Departamento de Controle do Espaço Aéreo - DECEA e o Ministério da Defesa.

O Regulamento Brasileiro de Aviação Civil Especial - RBAC -E nº 94 (ANAC, 20172), editado através da Resolução 410/2017 da ANAC, tem por escopo a viabilidade das operações com elevado nível de segurança. De acordo com a agência, as regras instituídas também têm por objetivo a promoção do desenvolvimento sustentável e seguro ao setor (ANAC, 2017 - 1).

Conforme a ANAC, além do Regulamento RBAC-E no. 94, outras normas precisam ser observadas. As instruções suplementares IS no. E94-001, IS no. E94-002 e IS no. E94.503-001 (ANAC, 2017-3) são algumas normas técnicas de procedimentos específicos que devem ser seguidos.

Tendo em vista a existência de elevado nível de complexidade e risco nas operações e equipamentos, os limites definidos na legislação tiveram por base regulamentações de autoridades de aviação civil de outros países, como a Federal Aviation Administration - FAA - dos Estados Unidos, Civil Aviation Safety Authority - CASA - da Austrália, e, por fim, European Aviation Safety Agency - EASA - da União Europeia.

${ }^{10}$ Art. 53. É competente o foro: (...) V - de domicílio do autor ou do local do fato, para a ação de reparação de dano sofrido em razão de delito ou acidente de veículos, inclusive aeronaves.

11 V. 11. 
Importante destacar que a partir de 03 de maio de 2017, qualquer aeronave não tripulada seja de uso recreativo, corporativo, comercial ou experimental, deverá se enquadrar nas regras definidas pela ANAC. Ressalta-se que há outras normas complementares como as da ANATEL - Agencia Nacional de Telecomunicações, DECEA - Departamento de Controle de Espaço Aéreo e o Ministério da Defesa.

Existem algumas premissas para a regulamentação do uso de drones (ANAC, 2017-1). Dentre eles, pode-se destacar a viabilização de operações (comerciais), desde que a segurança às pessoas permaneça preservada, minimização de ônus administrativo e burocracia, e a permissão de evolução conforme o setor se desenvolve.

A utilização na área agrícola vem crescendo ao longo do tempo, principalmente no uso de fertilizantes com o menor contato humano, gerando menores impactos na saúde. Para os agricultores, o uso de tecnologias como os drones no campo fez com que aplicassem a agricultura de precisão, baseada em instrumentos e recursos da tecnologia da informação para implementar a atividade econômica. $\mathrm{O}$ uso de drones facilita o monitoramento da produção e reduz os custos de investimento (Revista Pesquisa Fapesp, 2016).

Imprescindível destacar que a própria resolução dispõe de forma expressa a não possibilidade de drones em centros urbanos, salvo situações peculiares como no caso de segurança pública. É preciso um distanciamento de 30 metros da população local por questão de segurança individual. Essa proibição não ocorre em áreas agrícolas, geralmente não ou pouco habitáveis.

Ressalta-se ainda o uso da tecnologia para controle sanitário e ambiental, sendo cabível uma isenção específica definida na IS E94-002. Mesmo entendimento para o uso pelo Corpo de Bombeiros dos estados, onde o risco pelo não uso em determinado salvamento ou situação de perigo pode ocasionar um dano muito maior.

\section{ReSPOnSAbilidade Civil e Ambiental ACERCA dOS ReSí- DUOS}

Uma das grandes preocupações acerca do uso de tecnologias diz respeito ao descarte correto de seus resíduos. Nessa temática, questões envolvendo a responsabilização de fabricantes e usuários - responsabilidade compartilhada - precisa e merece ser debatida.

É imprescindível destacar uma breve análise acerca da evolução histórica no Brasil sobre a proteção ao meio ambiente. Para uma melhor compreensão da temática, é preciso abordar suscintamente os três aspectos que envolvem a responsabilidade ambiental, previsto no artigo 225 , parágrafo $3^{\circ}$. da Carta de $1988^{12}$ (BRASIL, 1988), abrangendo as áreas cível, penal e administrativa.

Com o início da conscientização ambiental nos primórdios dos anos 80, com a publicação da Política Nacional de Meio Ambiente (BRASIL, 1981), a sociedade brasileira passou a ter uma regulamentação mais específica acerca da preservação ambiental. Posteriormente, em 1988, foi

12 Art. 225. Todos têm direito ao meio ambiente ecologicamente equilibrado, bem de uso comum do povo e essencial à sadia qualidade de vida, impondo-se ao Poder Público e à coletividade o dever de defendê-lo e preservá- lo para as presentes e futuras gerações. [...] $\S 3^{\circ}$ As condutas e atividades consideradas lesivas ao meio ambiente sujeitarão os infratores, pessoas físicas ou jurídicas, a sanções penais e administrativas, independentemente da obrigação de reparar os danos causados. 
A utilização particular ou empresarial de drones no Brasil: responsabilidade civil e ambiental ou marco regulatório

promulgada uma nova ordem jurídica com a Constituição da República, o meio ambiente adquiriu status de direito difuso (Capítulo VI, do Título VIII), tornando-se um direito difuso e uma obrigação pela tutela de todos os entes e sociedade (BRASIL, 1988).

Ao abordar a temática responsabilidade, no âmbito cível, o texto constitucional prevê a modalidade objetiva daqueles causadores de condutas ou atividades lesivas ao meio ambiente. Ou seja, de acordo com Fiorillo (2015) e com o texto constitucional, não é exigido qualquer tipo de elemento subjetivo para a configuração da responsabilidade civil. Ademais, trata-se de responsabilidade solidária em respeito ao art. $3^{\circ}$, inciso I do Texto Maior ${ }^{13}$ (BRASIL, 1988).

Independentemente da obrigação de reparar os danos causados, poderão os infratores sofrer maiores penalidades, mesmo que não tenham agido de forma imprudente, negligente ou imperita.

Ainda com relação à responsabilidade, Fiorillo (2015) atenta a necessidade de respeito ao principio de direito norte-americano do due processo of law ${ }^{14}$. Importante destaque para que ocorra uma limitação do poder de polícia da Administração Pública.

A preocupação mundial na proteção e preservação do meio ambiente influenciam diretamente o cumprimento das normas brasileiras. O Brasil faz parte de tratados internacionais sobre a temática, já tendo inclusive sido sede de algumas conferências internacionais, como a Rio-92 (Senado, 2018) e a Rio+20 (2012), ambas ocorridas na cidade do Rio de Janeiro, em 1992 e 2012, respectivamente.

Segundo o Ministério do Meio Ambiente - MMA (2018), as ações que respeitam o meio ambiente e políticas que tenham por objetivo a sustentabilidade possuirão também responsabilidade socioambiental. Todos são responsáveis pela preservação ambiental: governos, empresas e cada cidadão.

Ademais, o MMA (2018) define produção sustentável como uma incorporação, ao longo de todo ciclo de vida de bens e serviços, objetivando o uso de alternativas melhores para minimizar custos ambientais e sociais. A preocupação acerca do meio ambiente ser preservado é tamanha que perfaz necessário o procedimento de licenciamento ambiental previsto na Lei Complementar 140/2011 (BRASIL, 2011). De acordo com a norma, qualquer atividade ou empreendimento utilizadores de recursos ambientais, efetiva ou potencialmente poluidores capazes de causar degradação ambiental devem ingressar com o procedimento administrativo.

Juntamente à questão da responsabilidade e da necessidade de licenciamento, é importante ressaltar que a definição de consumo sustentável. Definido pelo Programa das Nações Unidas para o Meio Ambiente (PNUMA, 1972), consume sustentável é o uso de bens e serviços que atendam às necessidades básicas, proporcionando uma melhor qualidade de vida, enquanto minimizam o uso de recursos naturais e materiais tóxicos, a geração de resíduos e a emissão de poluentes durante todo ciclo de vida do produto ou do serviço, de modo que não se coloque em risco as necessidades das futuras gerações.

Ao tratar de drones, a Resolução da ANAC de 2017 traz como regra sobre o descumprimento das normas estabelecidas a aplicação das sanções previstas na Lei $7.656 / 86^{15}$. Essa lei

\footnotetext{
${ }^{13}$ Art. $3^{\circ}$ Constituem objetivos fundamentais da República Federativa do Brasil: I - construir uma sociedade livre, justa e solidária; (...)

${ }^{14}$ O princípio do due process of law está previsto no art. $5^{\circ}$, incisos LIV e LV da Constituição da República de 1988 : LIV - ninguém será privado da liberdade ou de seus bens sem o devido processo legal; LV - aos litigantes, em processo judicial ou administrativo, e aos acusados em geral são assegurados o contraditório e ampla defesa, com os meios e recursos a ela inerentes;

${ }^{15}$ E94.17 - Descumprimento das regras estabelecidas. Resolução Anac RBAC E-94.
} 
descrita no regulamento trata do Código Brasileiro de Aeronáutica - CBA (BRASIL, 1986). De acordo com o disposto no regulamento, haverá a aplicação das sanções do CBA no caso de descumprimento das normas.

Com relação à responsabilidade penal quando da ocorrência de danos, o regulamento traz as disposições descritas no art. 33 da Lei de Contravenções Penais ${ }^{16}$ (BRASIL, 1941). Além disso, é possível aplicar também os tipos penais descritos no Código Penal (BRASIL, 1984), como o crime de dano previsto no art. $163^{17}$ do diploma.

Acerca da responsabilidade ambiental, o regulamento é silente. Não há qualquer previsão em seu texto acerca de um possível dano ambiental, do descarte de seus resíduos, ou qualquer outra matéria que atinja diretamente o Meio Ambiente.

Mediante a omissão legislativa, indaga-se acerca da possibilidade de aplicação da Politica Nacional de Resíduos Sólidos (BRASIL, 2011) bem como da Lei de Crimes Ambientais (BRASIL, 1998), que serão objeto de um trabalho futuro.

\section{Curiosidades Sobre OS VANT'S OU Drones na Europa}

Além da regulamentação já descrita no trabalho, no Brasil também é necessário o registro junto a Agencia Nacional de Telecomunicações - ANATEL, a fim de evitar interferências em outros aparelhos que necessitam de comunicações via satélite.

Algumas questões peculiares sobre a segurança no uso de drones já atingiu o Brasil e outros países já desenvolvidos e com regulamentação mais consolidada. Em alguns países europeus como Bélgica e Suécia já houve uma maior restrição ao uso ou até mesmo o banimento para aqueles amadores.

Segundo Botija (2018), as forças de segurança da Europa consideram os drones como uma real ameaça à segurança e não apenas um risco potencial. Para o autor, os riscos - de acordo com a Agência Europeia para segurança da aviação - EASA - podem ser detalhados como a capacidade de gerar acidentes e incidentes tanto no chão como no ar.

Botija (2018) aduz que, de forma efetiva, o usuário dos VANT's ou drones podem de forma involuntária causar danos e até mesmo agir contra a segurança coletiva.

Em junho de 2017, Portugal já apresentava um regulamento para o uso de drones, mas não possuía capacidade fiscalizatória. Por ser integrante da União Europeia, é signatário da legislação comum que prevê o registro de propriedade e identificação eletrônica do aparelho. Ocorre que àquela época não estava ainda vigente, encontrando-se em fase de consulta pública. A preocupação portuguesa ocorria pelos sucessivos incidentes com drones e a ausência de regras claras que dispusessem sobre responsabilização e controle dos equipamentos (DN, 2017).

Na Espanha, com a edição do Real Decreto 1036/2017, foi analisado o uso de drones e a relação com a segurança pública. De acordo com Botija (2018), o decreto foi dedicado de forma precisa à segurança, prevendo regras para que a execução de operações necessitem de comunicação prévia ao Ministério do Interior no prazo mínimo de dez dias da operação. A medida visa a restrição ou proibição de operações que podem ensejar riscos à proteção de pessoas ou até mesmo danos patrimoniais.

${ }^{16}$ E 94-701. Resolução ANAC RBA E 94.

17 Art. 163 - Destruir, inutilizar ou deteriorar coisa alheia: Pena - detenção, de um a seis meses, ou multa. 
A utilização particular ou empresarial de drones no Brasil: responsabilidade civil e ambiental ou marco regulatório

Incidentes ocorridos na Rússia também fizeram o governo local reavaliar o uso de drones em seus territórios, pleiteando uma regulamentação mais severa na Europa (SPUTNIKNEWS, 2018).

Em abril de 2018, foi publicada a informação em sítio eletrônico que a Agência Europeia de Segurança da Aviação - EASA - está para publicar uma legislação que proíbe o uso de drones recreativos sem licença nos países que fazem parte da comunidade europeia. Outros países que não integram a União Europeia como a Suíça tendem a adotar a mesma legislação (DroneDJ, 2018).

Portanto, constata-se que tanto no Brasil quanto em diversos países europeus há uma preocupação quanto a regulamentação do uso dos VANT's ou drones para evitar os abusos de fato e de direito que podem ocasionar instabilidade social e danos morais e materiais.

\section{CONSIDERAÇÕES FINAIS}

O acesso às novas tecnologias está cada vez mais comum e popular. Com a informação global e a necessidade de evolução tecnológica em curto espaço de tempo, objetos antes inalcançáveis se tornaram acessíveis. É o que ocorre com os VANT's ou drones, onde é possível visualizá-lo nas mais diferentes cidades e em diversas ocasiões. Com essa popularização, vêm os problemas a serem enfrentados, principalmente os jurídicos e as consequências do uso indiscriminado da tecnologia, o que gera dano nacional e transnacional.

Dentre os desafios enfrentados pelo setor da aviação civil está a concessão de certificação de aeronavegabilidade aos usuários, a fiscalização e punição dos infratores. Todavia, apesar da legislação ser um marco por sua relevância na área, é preciso um maior acesso às informações ali contidas de forma a evitar qualquer tipo de inoportuno.

Constata-se que muito ainda há de ser feito, principalmente a conscientização que não se trata de mero objeto de lazer e sim que há regras rígidas que precisam ser obedecidas para o melhor convívio de todos. Uma das atitudes positivas é que já existe no Brasil um setor para denúncias junto à $\mathrm{ANAC}^{18}$ (2017-4), como forma de tentar conter possíveis infratores.

As novas regras devem começar a serem adotadas em 2019 e tem por objetivo não a proibição total, mas tornar o seu usuário consciente que existem regras a serem seguidas e respeitadas, evitando assim problemas como o ocorrido no final de 2017 no aeroporto de Congonhas, São Paulo, Brasil (VEJA, 2017).

No Brasil, aplica-se de forma subsidiária os tipos penais descritos no Código Penal e na lei de contravenção penal (BRASIL, 1984), além de outros diplomas quando cabíveis. Acerca das questões envolvendo os resíduos, haverá também a aplicação da legislação de forma subsidiária, tendo em vista a omissão no regulamento.

Há uma necessidade de melhorias na aplicabilidade e divulgação das regras para pilotagem e uso dos drones pela população, independentemente do setor (recreativo ou não). Além disso, é de extrema urgência que ocorra um melhor acesso às informações pertinentes. Por fim, sugere-se que novas regulações para o uso, pilotagem, responsabilidade (civil, administrativa, penal e ambiental), além do descarte correto de resíduos sejam elaborados a fim de evitar maiores danos futuros.

\footnotetext{
${ }^{18}$ Fiscalização ANAC.
} 


\section{REFERÊNCIAS}

AGRICULTURA DE PRECISÃO. Revista Pesquisa. Drones sobre o campo. Disponível em: http://revistapesquisa.fapesp.br/2016/02/03/drones-sobre-o-campo-2/ Acesso em: 28 maio 2018.

ANAC - Agencia Nacional de Aviação Civil. Resolução 419/2017. Regras da ANAC para uso de drones entram em vigor. Disponível em: http://www.anac.gov.br/noticias/2017/regras-daanac-para-uso-de-drones-entram-em-vigor/release_drones_v2.pdf Acesso em: 20 maio 2018.

ANAC. Regulamento Brasileiro de Aviação Civil Especial - RBAC -E nº 94. Disponível em: http://www.anac.gov.br/assuntos/legislacao/legislacao-1/rbha-e-rbac/rbac/rbac-e-94-emd-00/ @@display-file/arquivo_norma/RBACE94EMD00.pdf Acesso em: 20 maio 2018.

ANAC. Legislação. Instruções Suplementares. Disponível em: http://www.anac.gov.br/assuntos/legislacao/legislacao-1/iac-e-is/is Acesso em: 29 maio 2018.

BOTIJA, Fernando G. Drones: seguridad pública y régimen sancionador. Revista Vasca de Administración Pública, n. 111, p. 271-310, mayo/ago. 2018. Disponível em: https:// www.euskadi.net/r61-s20001x/es/t59aWar/t59aMostrarFicheroServlet?t59aIdRevista=2\&

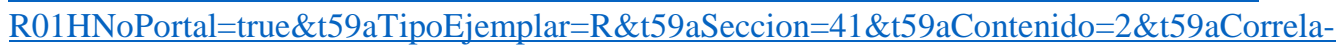

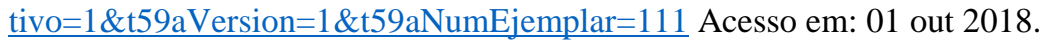

BRASIL. Política Nacional de Meio Ambiente. Lei no. 6.838/81. Disponível em: http:// www.planalto.gov.br/ccivil_03/Leis/L6938.htm Acesso em: 10 jun. 2018.

BRASIL. Código Penal. 1984. Disponível em: http://www.planalto.gov.br/ccivil_03/decretolei/Del2848compilado.htm Acesso em: 07 jun. 2018.

BRASIL. Codigo Brasileiro de Aeronautica. Lei n ${ }^{\circ}$ 7.656/86. Disponível em: http://www.planalto.gov.br/ccivil_03/Leis/L7565.htm Acesso em: 08 jun. 2018.

BRASIL. Constituição da República Federativa do Brasil. 1988. Disponível em: http:// www.planalto.gov.br/ccivil_03/constituicao/constituicao.htm. Acesso em: 30 maio 2018.

BRASIL. Código de Processo Civil Brasileiro. 2015. Disponível em: http://www.planalto.gov.br/ccivil_03/_ato2015-2018/2015/lei/113105.htm Acesso em: 09 jun. 2018.

BRASIL. Decreto-lei 3.688/41. Lei de Contravenções Penais. Disponível em: http://www.planalto.gov.br/ccivil_03/decreto-lei/Del3688.htm Acesso em: 10 jun. 2018.

BRASIL. Lei no 11.186/2006. Cria a Agencia Nacional de Aviação Civil - ANAC. Disponível em: http://www.planalto.gov.br/ccivil_03/_ato2004-2006/2005/lei/111182.htm Acesso em: 30 maio 2018.

BRASIL. Lei Complementar $\mathbf{n}^{\circ}$ 140/2011. Disponível em: http://www.planalto.gov.br/ccivil_03/Leis/LCP/Lcp140.htm Acesso em: 10 jun. 2018.

BRASIL. Fale com a ANAC. Disponível em: http://www.anac.gov.br/fale-com-a-anac/ copy_of fale-com-a-anac Acesso em: 29 maio 2018.

CANOTILHO, José Joaquim Gomes. Direito Constitucional. 6. ed. Coimbra: Almedina. 1993.

DIDIER JR., Fredie. Curso de Direito Processual Civil. V. 1. ed. Salvador: JusPodivm, 2018.

DN. Diário de Notícias. Lei mais rígida sobre uso de drones marca passo na agência europeia. Disponível em: https://www.dn.pt/sociedade/interior/lei-mais-rigida-sobre-uso-de-dronesmarca-passo-na-agencia-europeia-8573022.html Acesso em: 29 maio 2018. 
A utilização particular ou empresarial de drones no Brasil: responsabilidade civil e ambiental ou marco regulatório

DRONE DJ. Hobby drone pilots in the EU and Switzerland will soon need a license. Disponível em: https://dronedj.com/2018/04/19/hobby-drone-pilots-in-the-eu-and-switzerland-willsoon-need-license/ Acesso em: 29 maio 2018.

FEDERAL Aviation Administration. Disponível em: https://www.faa.gov/. Acesso em: 29 maio 2018.

FIORILlO, Celso Antônio P. Curso de Direito Ambiental Brasileiro. 16. ed. São Paulo: Saraiva, 2015.

MERCADRONE. 13 áreas diferentes que atuam com drones. Disponível em: http://blog.mercadrone.com.br/index.php/2016/08/11/13-areas-diferentes-que-ja-atuam-com-drones/ Acesso em: 26 maio 2018.

MINISTÉRIO DO MEIO AMBIENTE. Responsabilidade Socioambiental. Brasil, 2016. Disponível em: http://www.mma.gov.br/responsabilidade-socioambiental. Acesso em: 03 jun. 2018.

NERY JR, Nelson e ANDRADE NERY, Rosa Maria. Código de Processo Civil Comentado. $17^{\mathrm{a}}$.ed. São Paulo: Saraiva, 2018.

PNUMA. Programa das Nações Unidas para o Meio Ambiente. 1972. Disponível em: https:// nacoesunidas.org/agencia/pnuma/. Acesso em: 08 jun. 2018.

SENADO FEDERAL. Conferência Rio-92 sobre o meio ambiente do planeta: desenvolvimento sustentável dos países. Disponível em: http://www.senado.gov.br/noticias/Jornal/emdiscussao/rio20/a-rio20/conferencia-rio-92-sobre-o-meio-ambiente-do-planeta-desenvolvimentosustentavel-dos-paises.aspx Acesso em: 10 jun. 2018.

SILVA, José Afonso da. Curso de Direito Constitucional Positivo. 38 ed. rev. São Paulo: Malheiros, 2015.

SLAIBI FILHO, Nagib. Direito Constitucional. Rio de Janeiro: Forense. 2004.

SPUTNIK NEWS. Rússia quer regulamentação mais severa sobre drones na Europa. Disponível em: https://br.sputniknews.com/russia/2018021610546728-russia-drones-regulamentacao/ Acesso em: 29 maio 2018.

STF. Supremo Tribunal Federal. AG .Reg. no Recurso Extraordinário 1.045.719 Minas Gerais. Disponível em: http://redir.stf.jus.br/paginadorpub/paginador.jsp?docTP=TP\&do$\underline{\mathrm{cID}=14330381}$ Acesso em: 31 maio 2018.

RIO + 20. Anais da Conferencia. 2012. Disponível em: http://www.rio20.gov.br/ Acesso em: 10 jun. 2018.

VASCONCELOS, P. S.; CARPIO, L. G. T. 2014. Estimating the economic costs of electricity deficit using input-output analysis: the case of Brazil. Disponível em: https://www.tandfonline.com/doi/abs/10.1080/00036846.2014.982858 Acesso em: 30 maio 2018.

VEJA. Drone fecha aeroporto de Congonhas por duas horas. Disponível em: https:// veja.abril.com.br/brasil/drone-fecha-aeroporto-de-congonhas-por-duas-horas/ Acesso em: 29 maio 2018.

WAMBIER, Luiz Roberto. Curso Avançado de Processo Civil. 17. ed. São Paulo: Revista dos Tribunais, 2017.

Recebido em: 08 out. 2018.

Aceito em: 03 dez. 2019. 